\title{
A few (million) dollars more can keep Galileo exploring
}

Washington. The Jupiter mission of the US Galileo spacecraft may be extended beyond its planned shutdown next year to allow more detailed study of the planet's most intriguing moons, Europa and Io.

Spacecraft managers presented the plan at last week's meeting of the National Aeronautics and Space Administration (NASA) advisory committee for solar system exploration. The idea is still a long way from final approval but it was received enthusiastically by the committee, which is made up of scientists from outside the agency.

Steven Squyres of Cornell University said: "I'm hard pressed to think of a more cost-effective way we could spend our money." This opinion was shared by all the panel members. Marcia Neugebauer of the Jet Propulsion Laboratory (JPL) in Pasadena, California, said "it's stupid to turn off spacecraft" while they are returning useful data.

The Galileo Extended Mission, which was conceived in recent months at JPL, calls for the spacecraft to make between six and eight additional swings past the icy moon Europa in 1998. Galileo is already scheduled to encounter Europa three more times before the end of the Jupiter mission in November 1997.

The extra fly-bys, if approved, would be at closer range, would cover parts of the moon not seen earlier during the mission, and would offer dramatic improvements in image resolution, to between 2 and 20 metres. There would also be a fly-by close to the volcanic moon Io, which was not viewed at close range earlier because of problems with Galileo's tape recorder.

Scientific interest in Europa has been heightened by recent Galileo pictures sug-

\section{Mars research boost}

Washington. NASA hopes to spend an extra $\$ 1$ million next year on the analysis of meteorites believed to have originated on Mars. The space agency expects to solicit research proposals in November, perhaps in cooperation with the National Science Foundation and the Smithsonian Institution, who jointly administer the existing meteorite research programme.

A study team at NASA's Johnson Space Center in Houston has also jumped on the Mars bandwagon, kicking off an investigation into how the agency might conduct a human visit to the planet in the next century. A recent crash exercise to review robotic spacecraft plans for Mars (see Nature, 382, $565 ; 1996)$ produced only a list of general options - including a sample return in 2003 - with no price tags attached. gesting that liquid water, or perhaps warm ice, lies beneath the moon's outer crust, as has long been suspected. Those pictures have a resolution of 1.6 kilometres.

Torrence Johnson, Galileo project scientist, said a two-year extended mission could cost as little as $\$ 15$ million. To achieve that, the project would streamline its ground

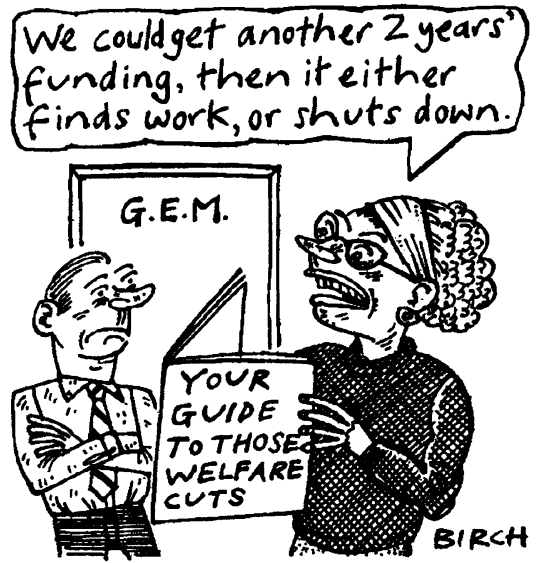

operations and cut its scientific and engineering teams to one-fifth of their present size.

The project would need no additional funding until 1998, he said. That would give NASA time to find the extra money. One option would be to run the extended mission for less than the full two years.

During the period until 1998 the spacecraft's health will be monitored. There is no known problem that would prevent the spacecraft from operating normally through 1999.

Extending missions beyond their planned lifetimes has become a financial problem for the agency, which has postponed until next month a decision on whether to extend several astronomy missions (see Nature 382, 193; 1996)

So strapped for cash is the agency's science office that it decided last week to postpone indefinitely a request for proposals for science instruments for the planned Pluto Express mission, which had been loosely targeted for early next century. The reason given was "budgetary uncertainties".

NASA officials say the Pluto mission is not affordable, given a "flat" budget over the next few years, which many believe is the best the agency can hope for.

At last week's advisory committee meeting, Wes Huntress of NASA painted an ironic picture. Despite an "extraordinary year" of scientific and public-relations successes, he said, NASA's science programme was now experiencing the "fastest declining budget of any in the agency".

Tony Reichhardt

\section{NASA aircraft move won't save money, audit finds}

San Francisco. A controversial plan to move aircraft used by researchers at NASA sites to one centre will cost $\$ 11.3$ million to implement and save very little money, says a NASA audit.

NASA's plan would move research aircraft from sites in Virginia, Ohio, Mississippi and northern California to Dryden Flight Research Center at Edwards Air Force Base in southern California. Daniel Goldin, NASA's administrator, had proposed the move to help cut the agency's budget by $\$ 3$ million over the next three years.

Under the plan, all aircraft used for scientific platforms, transport or educational purposes would go to Dryden, where NASA would build a new $\$ 2.8$ million computer network system. The plan also involved building helicopter telemetry and radar facilities costing \$990,000 at Ames Research Center in northern California.

NASA's Office of the Inspector General analysed the plan and concluded that these and other costs would rob it of any savings and efficiencies.

Officials in the San Francisco area have fought the move, saying that Ames - which would lose nine research aeroplanes would suffer most. Representative Anna Eshoo (Democrat, California) is concerned that the loss of most of Ames' aircraft operations would threaten the future of the adjoining Moffett Federal Airfield. She criticized NASA for lack of concern about the impact the move would have on research programmes at Ames.

Ames had been a favoured site for a proposed $\$ 2.5$ billion wind-tunnel complex for the development of subsonic airliners, but the plan fell through last year.

NASA officials had estimated that moving the aircraft to one site would save $\$ 23.3$ million. The inspector general's report concluded that savings would amount to just $\$ 218,049$. The report said: "If the cost of money is factored in, we project that NASA would never recover its financial investment." NASA officials were unavailable for comment.

NASA has managed Moffett as a shared facility for several government agencies and their contractors since the Navy abandoned it in 1994. The Bureau of Alcohol, Tobacco and Firearms, the United States Geological Survey, Lockheed Martin Missiles and Space, the American Red Cross and the Air National Guard are among its tenants. But Moffett has had some trouble lately in its efforts to diversify. A plan to sponsor air cargo carriers who are members of the Civil Reserve Air Fleet at the site has been temporarily scrapped after complaints from local residents.

Sally Lehrman 